\title{
Totally extraperitoneal inguinal hernia repair in patients with hemophilia and von Willebrand disease. Prospective controlled study
}

\author{
Konrad Pielaciński ${ }^{1}$, Bartosz Puła ${ }^{2}$, Andrzej B. Szczepanik ${ }^{1}$ \\ ${ }^{1}$ Department of General, Oncologic and Metabolic Surgery, Institute of Hematology and Transfusion Medicine, Warsaw, Poland \\ ${ }^{2}$ Department of Hematology, Institute of Hematology and Transfusion Medicine, Warsaw, Poland
}

Videosurgery Miniinv 2021; 16 (3): 552-559

DOI: https://doi.org/10.5114/wiitm.2021.103953

\begin{abstract}
Introduction: Laparoscopic surgery is associated with several advantages. Surgical procedures in hemophilia or von Willebrand patients without replacement therapy (RT) to correct clotting factor deficiency may result in serious, life-threatening hemorrhagic episodes. Clotting factor concentrates improve hemostatic control but bleeding risk in major invasive procedures remains high.

Aim: Evaluation of totally extraperitoneal inguinal hernia repair (TEP-IHR) in patients with congenital hemorrhagic disorders $(\mathrm{H})$ and comparison with results for non-hemophiliacs $(\mathrm{NH})$ with regard to bleeding, postoperative pain, hernia recurrence, surgery time, demand for painkillers, hospital stay and recovery time.

Material and methods: The prospective controlled trial included 67 consecutive male patients scheduled for TEP-IHR between January 2010 and December 2018. Surgery was performed in groups $H(n=22)$ and $N H(n=45)$. Full study inclusion criteria were met by 65 patients (22 and 43 in $\mathrm{H}$ and $\mathrm{NH}$ groups respectively). Follow-up was carried out on the $1^{\text {st }}, 2^{\text {nd }}$, and $7^{\text {th }}$ day and in the 1st and 3rd month postoperatively.

Results: TEP-IHR was successful for all patients. No life-threatening bleeding occurred and no patient required red blood cell transfusions or reoperation. No hernia recurrence was reported. No statistically significant differences were observed between the groups with regard to surgery duration, postoperative hematoma frequency and demand for painkillers. In the H group, pain intensity was significantly higher during the first postoperative month and hospitalization and recovery were significantly longer.

Conclusions: TEP-IHR in hemophiliacs with RT is feasible and as effective for preventing hernia recurrence as in $\mathrm{NH}$-patients. In hemophiliacs risk of bleeding complications and demand for painkillers are comparable to non-hemophiliacs although pain is more intense.
\end{abstract}

Key words: hemophilia, hernia recurrence, totally extraperitoneal inguinal hernia repair, bleeding diathesis, hemorrhagic complications.

\section{Introduction}

Laparoendoscopic inguinal hernia repair has significant advantages over open surgery. Patients mostly benefit from lower risk of surgical-site infection and postoperative pain, faster recovery and better cosmetic effect. The technique therefore is frequently applied for patients with no contraindications to general anesthesia or laparoendoscopy (such as inability to tolerate pneumoperitoneum). The current belief is that cardiovascular and pulmo-

\section{Address for correspondence}

Konrad Pielaciński MD, Department of General, Oncologic and Metabolic Surgery, Institute of Hematology and Transfusion Medicine, Warsaw, Poland, phone: +48 22 3496268, e-mail: konpiel@tlen.pl 
nary-related comorbidities as well as uncorrectable coagulopathy (bleeding disorders included) are also contraindicated [1-7]. Congenital bleeding disorders are quite rare diseases characterized by deficiency of certain blood coagulation factors. These deficiencies result in a tendency to spontaneous or perioperative bleeding, the intensity of which is proportional to the coagulation factor deficiency. The most common congenital bleeding disorders are hemophilia A (factor VIII deficiency), hemophilia B (factor IX deficiency), and von Willebrand disease (vWD) (a complex disorder the components of which may include abnormalities of von Willebrand factor function, quantity or quality of factor VIII, and reduced platelet count). Depending on the severity of the clotting factor deficiency, hemophilia may be severe (factor VIII or IX activity $<1 \mathrm{IU} / \mathrm{dl}$ ), moderate $(1-\leq 5$ $\mathrm{IU} / \mathrm{dl}$ ) or mild (>5-<50 IU/dl). vWD is classified into types 1,2 , and 3 . Type 1 vWD is generally the mildest and type 3 the most severe. Forms of type 2 are intermediate in severity [8-11]. In the perioperative period patients with congenital bleeding disorders require specific pharmacological treatment, most often consisting in supplementation of the deficient coagulation factor. Perioperative hemostasis is quite a challenge for the multidisciplinary team (surgeon, hematologist) because even if the correct concentration of deficient factors is maintained, there remains a high risk of bleeding complications. Therefore, due to fear of life-threatening bleeding, open surgical techniques are frequently applied because hemostatic control is easier than with laparoendoscopic techniques, although the latter are more beneficial for patients [6, 8-16].

\section{Aim}

The primary goal was to evaluate the risk of hemorrhagic complications and hernia recurrence in patients with congenital bleeding disorders and without hemorrhagic diathesis subjected to totally extraperitoneal inguinal hernia repair (TEP-IHR). Secondary goals were to compare postoperative pain, analgesic drug demand, operative time, hospital stay and recovery in these two groups of patients.

\section{Material and methods}

This prospective study comprised patients admitted for elective inguinal hernia repair in the period 2010-2018. The study group (hemophiliacs, H group) consisted of patients with congenital bleeding disorders; the control group consisted of patients without bleeding disorders (non-hemophiliacs, $\mathrm{NH}$ group). Patients operated on in the same week were assigned to the appropriate study groups. Men over 18 years of age with primary or recurrent, unilateral or bilateral inguinal hernias were included into the study. Excluded from the study were patients after pelvic surgery from midline incisions below the umbilicus or with irreducible or incarcerated inguinal hernia or inguinoscrotal hernias. The participants were asked to give written informed consent and the study was approved by the local ethics committee. Obligatory antibiotic prophylaxis was administered at $2 \mathrm{~g}$ of cefazolin in a single dose. Prophylaxis of thromboembolic events (nadroparin $0.3 \mathrm{ml}$, s.c.) was conducted for patients with no bleeding disorders. Patients with bleeding disorders were given clotting factor concentrates (CFCs) for 8 days, intravenously every $12 \mathrm{~h}$ at an adjusted dose. Hemophilia A patients were given factor VIII (at a dose calculated to achieve the concentration of $80-100 \mathrm{IU} / \mathrm{dl}$ on surgery day, 60-80 IU/dl on days 1-3, 40-60 IU/dl on days 4-7). Hemophilia $B$ patients were given factor IX to achieve the concentration of $60-80 \mathrm{lU} / \mathrm{dl}$ on the day of surgery, 40-60 IU/dl on post-operative days $1-3$, and 30-50 IU/dl on days $4-7$. Von Willebrand disease patients were given von Willebrand factor and factor VIII in the same mode as hemophilia A patients [8, 10-14].

On surgery day, hemophilia A and VWD patients used approximately $50 \mathrm{lU} / \mathrm{kg}$ of clotting factor, and in hemophilia B patients the amount was approximately $40 \mathrm{lU} / \mathrm{kg}$. During the next 7 days, the clotting factor dose was adjusted following the outcome of morning concentration measurement. Repair surgery was performed with TEP technique using the Ultrapro mesh implant (Ethicon, Diegem Belgium) with fixation only for defect size larger than $3 \mathrm{~cm}$ (AbsorbaTack Fixation Device (Covidien, Dublin Ireland). Pain intensity was assessed on the Numerical Rating Scale (NRS) and paracetamol was used to relieve pain. Patients were allowed to walk and drink 4-6 h after the procedure. Discharge occurred not earlier than $24 \mathrm{~h}$ after the operation and depended on the patient's general condition. Study data were collected on the $1^{\text {st }}, 2^{\text {nd }}$, and $7^{\text {th }}$ days and 1 and 3 months after the procedure. All patients were warned against heavy lifting for a month and after that no restrictions on physical activity were 
imposed. For patients with bleeding disorders, the hemostatic effect of RT was assessed intraoperatively by determining bleeding intensity during the procedure as well as occurrence of bleeding complications in the postoperative period. All TEP-IHR procedures were performed under general anesthesia, using a conventional three-port midline technique without the use of a balloon dissector [17]. In direct inguinal hernia procedures, the extended transversalis fascia was retracted and ligated with absorbable sutures. In indirect inguinal hernia procedures the hernial sac was completely dissected from the spermatic cord. Type of hernia was determined intraoperatively using the EHS (European Hernia Society) groin hernia classification. No drainage of the surgical site was performed [18].

\section{Statistical analysis}

The statistical analysis was performed using Prism 7.0 (GraphPad, La Jolla, CA, USA). The D'Agostino-Pearson normality test was used to assess the data distributions. The unpaired t-test was used for patient age group comparison. The Mann-Whitney $U$-test was applied to compare the groups of data that did not meet the assumptions of the parametric test. The $\chi^{2}$ test was used for comparison of quali-

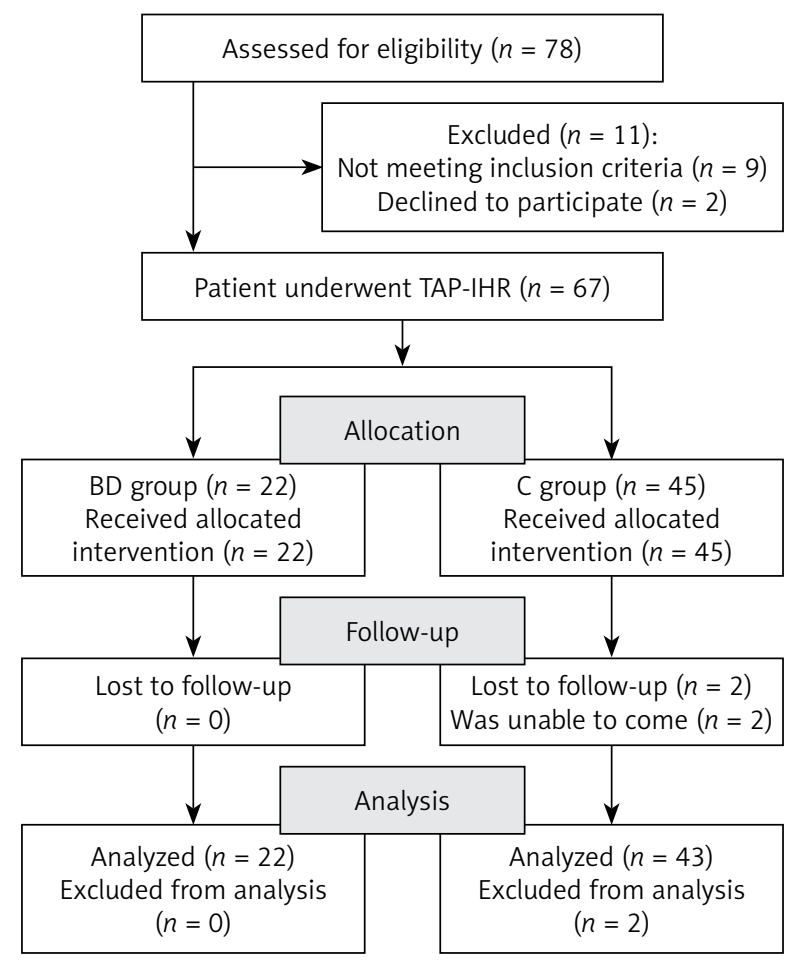

Figure 1. Study flow chart tative variables. Results were considered statistically significant when $p<0.05$ in all the analyses.

\section{Results}

Seventy-eight patients reported for elective surgery, including 27 patients with bleeding disorders. Five patients were excluded from the study group with hemorrhagic disorders ( $\mathrm{H}$ group): 3 due to scrotal hernia, and 2 declined to participate. The $\mathrm{H}$ group consisted of 22 patients. A control group comprised 51 patients without bleeding disorders ( $\mathrm{NH}$ group), but 6 were excluded from the study: 2 due to contraindications to general anesthesia and 4 due to scrotal hernia. Finally, the NH group consisted of 45 patients. All patients of the $\mathrm{H}$ group and 43 (95.6\%) of the $\mathrm{NH}$ group reported for the scheduled follow-up examination. The results of $22 \mathrm{H}$ group patients and $43 \mathrm{NH}$ group patients were subject to analysis. The results of the search and the process of screening for inclusion in the study are illustrated in the study flow chart (Figure 1). No statistically significant differences in the distribution of traits between the study groups were found except for health condition assessed by the American Society of Anesthesiologists Physical Status Classification System (ASA) (Table I). The $\mathrm{H}$ group comprised 16 hemophilia A patients (HA patients) (6 severe, 10 mild), 3 severe hemophilia B (HB patients) and 3 von Willebrand ( $v W D$ patients) (2 patients with type 1 and 1 with type $2 a$ ).

\section{Factor supplementation}

On surgery day the median clotting factor supplementation was as follows: in HA patients $100 \mathrm{IU} / \mathrm{kg}$ (82, 41), in HB patients $152 \mathrm{IU} / \mathrm{kg}(135,197)$, in vWD patients $56 \mathrm{IU} / \mathrm{kg}(51,78)$. On postoperative days $1-3$, the median factor supplementation was: in HA patients $86 \mathrm{IU} / \mathrm{kg}(28,122)$, in $\mathrm{HB}$ patients $135 \mathrm{IU} / \mathrm{kg}$ (36, 197), in VWD patients 40/IU/kg $(17,57)$. On postoperative days $4-7$, the median factor supplementation was as follows: in HA patients $27 \mathrm{IU} / \mathrm{kg}(0,80)$, in HB patients $34 \mathrm{IU} / \mathrm{kg}(0,72)$, in vWD patients $20 \mathrm{IU} / \mathrm{kg}(0,57)$ (Table II).

Median clotting factor levels are presented in Figure 2 .

In hemophiliacs the RT hemostatic effect assessed intraoperatively was found to be very good. In both $\mathrm{H}$ and $\mathrm{NH}$ groups, none of the patients experienced life-threatening bleeding and none required red blood cell transfusions or reoperation due to 
Table I. Characteristics of the patient population. Data are presented as number of patients $(n)$ and percentages (\%)

\begin{tabular}{|c|c|c|c|}
\hline Parameter & $\begin{array}{l}\text { H group } \\
(n=22)\end{array}$ & $\begin{array}{l}\text { NH group } \\
(n=43)\end{array}$ & $P$-value \\
\hline Age [years] median, range & $51,19-70$ & $49,26-75$ & $0.3041^{a}$ \\
\hline BMI [kg/m²]: & & & $0.0426^{b}$ \\
\hline Normal $(18.5 \leq \mathrm{BMI} \leq 24.9)$ & $13(59.1 \%)$ & $22(51.2 \%)$ & \\
\hline Overweight $(25 \leq \mathrm{BMI} \leq 29.9)$ & $6(27.3 \%)$ & $17(39.5 \%)$ & \\
\hline Obese $(\mathrm{BMI}>30)$ & $3(13.6 \%)$ & $4(9.3 \%)$ & \\
\hline Previous surgery: & & & $0.8036^{b}$ \\
\hline Yes & $8(36.4 \%)$ & $17(39.5 \%)$ & \\
\hline No & $14(63.6 \%)$ & $26(60.5 \%)$ & \\
\hline ASA class: & & & $<0.001^{b}$ \\
\hline I & $0(0 \%)$ & $21(48.8 \%)$ & \\
\hline$\|$ & $16(72.7 \%)$ & $17(39.5 \%)$ & \\
\hline III & $6(27.3 \%)$ & $4(9.2 \%)$ & \\
\hline Unilateral hernias & $16(72.7 \%)$ & $29(67.5 \%)$ & $0.6622^{b}$ \\
\hline Bilateral hernias & $6(27.3 \%)$ & $14(32.5 \%)$ & \\
\hline Recurrent hernias & $4(18.2 \%)$ & $9(20.9 \%)$ & \\
\hline Total number of operations & $28(100 \%)$ & $57(100 \%)$ & \\
\hline Hernia side: & & & $0.8003^{b}$ \\
\hline Right sided & $17(60.7 \%)$ & $39(68.2 \%)$ & \\
\hline Left sided & $11(39.3 \%)$ & $18(31.8 \%)$ & \\
\hline \multicolumn{4}{|l|}{ Hernia type - EHS classification: } \\
\hline Lateral: & $17(60.7 \%)$ & $38(66.6 \%)$ & $0.9885^{b}$ \\
\hline I & $5(17.8 \%)$ & 11 (19.3\%) & \\
\hline II & 10 (35.7\%) & $23(40.3 \%)$ & \\
\hline III & $2(7.1 \%)$ & 4 (7.0\%) & \\
\hline Medial: & 9 (32.1\%) & 19 (33.3\%) & $0.7685^{b}$ \\
\hline I & $1(3.6 \%)$ & $3(5.3 \%)$ & \\
\hline II & 5 (17.8\%) & 9 (15.8\%) & \\
\hline III & $2(7.1 \%)$ & 7 (12.3\%) & \\
\hline
\end{tabular}

${ }^{a}$ Calculated with unpaired $t$ test, ${ }^{b}$ calculated with $\chi^{2}$ test. EHS - European Hernia Society, ASA - American Society of Anesthesiologists Physical Status Classification System, BMI - body mass index $\left(\mathrm{kg} / \mathrm{m}^{2}\right)$.

Table II. Median clotting factor supply for $1 \mathrm{~kg}$ of body weight per day

\begin{tabular}{|lccc|}
\hline Patients & $\begin{array}{c}\text { Day of surgery } \\
\text { median IU/kg (range) }\end{array}$ & $\begin{array}{c}\text { Days 1-3 post-op. } \\
\text { median IU/kg (range) }\end{array}$ & $\begin{array}{c}\text { Days 4-7 post-op. } \\
\text { median IU/kg (range) }\end{array}$ \\
\hline HA & $100(82-141)$ & $86(28-122)$ & $27(0-80)$ \\
\hline HB & $152(135-197)$ & $135(36-197)$ & $34(0-72)$ \\
\hline VWD & $56(51-78)$ & $40(17-57)$ & $20(0-57)$ \\
\hline
\end{tabular}




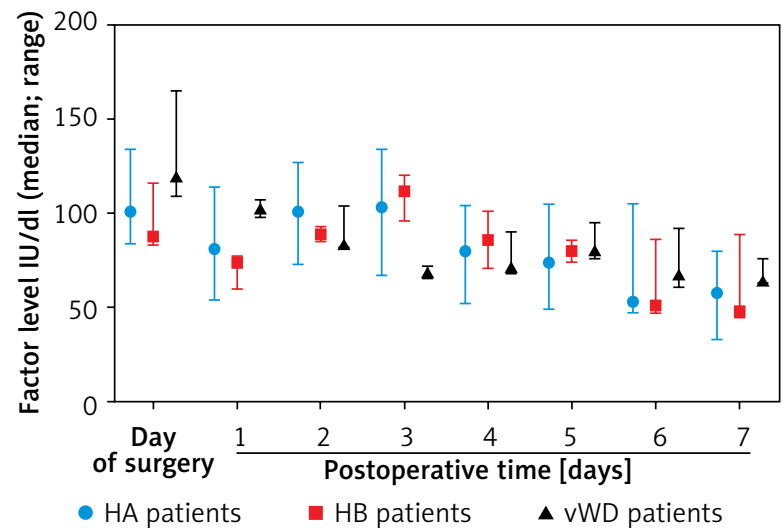

Figure 2. Median clotting factor levels, median $\mathrm{IU} / \mathrm{dl}$ and range

bleeding complications. No statistically significant differences between the study groups were found with regard to incidence of postoperative bleeding complications. Local hematomas were observed in 11 patients (4 (18.2\%) from the $\mathrm{H}$ group and 7 (13.9\%) from the $\mathrm{NH}$ group) and subcutaneous hematomas in 8 (3 (13.6\%) from the $\mathrm{H}$ group and 5 (11.6\%) from the $\mathrm{NH}$ group) (Table III). In the $\mathrm{H}$ group patients who developed local hematomas (1 with severe hemophilia B, 2 with severe hemophilia $A$ and 1 with mild hemophilia), the achieved concentration of deficient clotting factors was within recommended values. The difference in factor VIII levels between hemophilia A patients with hematomas and other hemophilia A surgical patients was statistically insignificant (mean $75.7 \pm 17.4 \%$ vs. $89.3 \pm 14.11 \%$, $p=0.1066$, Mann-Whitney test). No such calculations were performed for hemophilia $B$ due to the small number of patients (three). No delayed bleeding was observed for patients in the $\mathrm{H}$ group. No hernia recurrence in the study groups was recorded during 3-month follow-up. No statistically significant differences between $\mathrm{H}$ and $\mathrm{NH}$ groups were recorded with regard to median duration of unilateral and bilateral TEP-IHR; 66 vs. $67 \mathrm{~min}$ and 127 vs. $105 \mathrm{~min}$, respectively. Peritoneal tears were observed with comparable frequency in both groups, with no statistically significant difference (Table IV). Return to preoperative level of activity occurred on the third postoperative day. In the $\mathrm{NH}$ group however it was observed more frequently $(p=0.037)$ and more patients returned to the preoperative level of activity earlier than in the $\mathrm{H}$ group (i.e. $3^{\text {rd }}$ day). Duration of postoperative hospitalization in the $\mathrm{H}$ group lasted 7 days and was significantly longer $(p<0.0001)$ as compared to the $\mathrm{NH}$ group (3 days) (Table IV). On postoperative days 1,2 , and 7 most patients report-

Table III. Hemorrhagic complications

\begin{tabular}{|lccc|}
\hline Parameter & H group $(n=22)$ & NH group $(n=43)$ & $P$-value \\
\hline Local hematoma: & $4(18.2 \%)$ & $7(13.9 \%)$ & $0.6548^{\mathrm{b}}$ \\
\hline Umbilicus & $1(4.5 \%)$ & $0(\%)$ & \\
\hline Groin & $1(4.5 \%)$ & $2(4.6 \%)$ & \\
\hline Spermatic cord/scrotal & $2(9 \%)$ & $5(11.6 \%)$ & $0.0526^{\mathrm{b}}$ \\
\hline Subcutaneous hematoma & $3(13.6 \%)$ & $5(11.6 \%)$ & \\
\hline
\end{tabular}

${ }^{b}$ Calculated with $\chi^{2}$ test.

Table IV. Overall comparison of surgery-related and outcome parameters

\begin{tabular}{|lccc|}
\hline Parameter & H group & NH group & $P$-value \\
\hline Duration of operation unilateral hernias [min]: median (range) & $66(51-106)$ & $67(40-130)$ & $0.8373^{\mathrm{a}}$ \\
\hline Duration of operation bilateral hernias [min]: median (range) & $127(76-172)$ & $105(81-168)$ & $0.1654^{\mathrm{a}}$ \\
\hline \begin{tabular}{l} 
Peritoneal laceration: \\
\hline Yes
\end{tabular} & $9(40.9 \%)$ & $25(58.1 \%)$ & $0.1882^{\mathrm{b}}$ \\
\hline No & $13(59.1 \%)$ & $18(41.9 \%)$ & $0.8409^{\mathrm{a}}$ \\
\hline Analgesic consumption in $1^{\text {st }}$ postoperative week: median (range) & $1.5(0-3)$ & $1.0(0-3)$ & $0.037^{\mathrm{a}}$ \\
\hline Return to pre-operative activity [days]: median (range) & $3(1-5)$ & $3(0-5)$ & $<0.0001^{\mathrm{a}}$ \\
\hline Length of postoperative stay [days]: median (range) & $7(6-8)$ & $3(1-5)$ & $<$ \\
\hline
\end{tabular}


ed pain intensity at the surgical site (0-6 according to NRS) (Figure 3). During the first and third month, pain was reported sporadically by single patients. During the first month, the pain intensity reported by $\mathrm{H}$ group patients was significantly greater than that reported by the $\mathrm{NH}$ group $-1(0,6)$ vs. $0(0,4)$ $(p=0.0210)$, respectively. At the $1^{\text {st }}, 2^{\text {nd }}$ and $7^{\text {th }}$ days and the $3^{\text {rd }}$ month, the differences in pain intensity between study groups were statistically insignificant (Mann-Whitney U-test).

No statistically significant difference was recorded between the groups with regard to the amount of analgesic (paracetamol g per/day) administered on the $1^{\text {st }}, 2^{\text {nd }}$ and $7^{\text {th }}$ days following surgery $(\mathrm{H}$ vs. $\mathrm{NH}$; $1.5(0,3)$ vs. $1.0(0,3)$ ), median (minimum level, upper level) Mann-Whitney test. As concerns analgesic management in the $1^{\text {st }}$ and $3^{\text {rd }}$ months following surgery, differences in the demand for painkillers were not assessed due to the low number of patients who reported pain.

\section{Discussion}

From the historical perspective, surgical management of patients with congenital hemorrhagic disorders has always been burdened with high risk of failure. In the mid- $20^{\text {th }}$ century life-threatening bleeding and deaths were reported for $66 \%$ of hemophilia patients as a result of minor or major surgical interventions [8, 19-23]. Nowadays, in these patients substitution of deficient blood clotting factors is applied in the perioperative period to improve hemostatic control $[8,12,14,23]$. Although the use of clotting factor concentrates has markedly reduced the percentage of bleeding complications to $10 \%$ and the mortality rate to $4.5 \%$, hemophilia patients are still at higher risk of bleeding, delayed wound healing and postoperative infections. If surgery is required, the open approach is frequently selected as offering a better chance of achieving local hemostasis than the laparoendoscopic technique, although the latter is associated with better outcome (faster recovery, less operative trauma, cosmetic benefits, reduced postoperative pain, shorter hospital stay) $[6,8,15,16$, 21, 24-26]. Although the dose and duration of CFC administration remain controversial, in 2010, we performed several pioneer TEP-IHR procedures in close cooperation with hematologists and according to the guidelines for hemophiliacs undergoing surgery. No significant technical difficulties were reported and

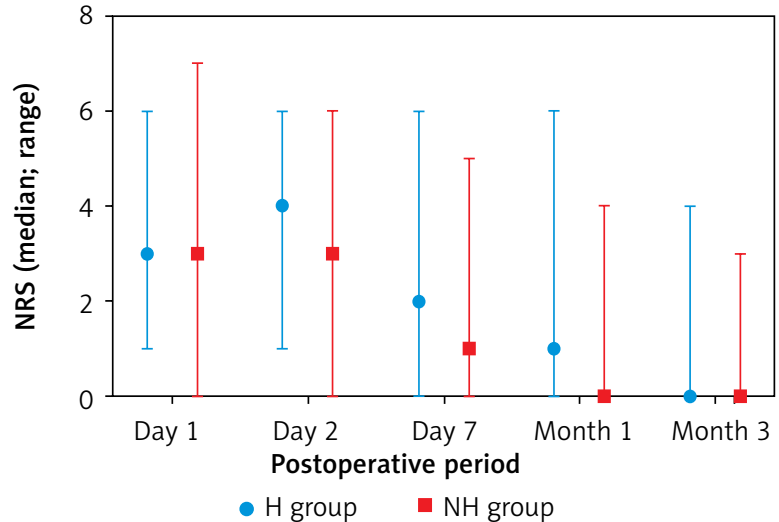

Figure 3. Pain intensity in postoperative period (NRS) median and range

no bleeding complications occurred. Postoperative follow-up demonstrated the procedures to be successful for preventing hernia recurrence. Our above observations and the results of the works published at that time allowed us to state that the use of laparoendoscopic techniques in patients with congenital bleeding disorders is feasible and effective and is not associated with a higher risk of adverse events than open approaches [5, 12, 16, 23, 25]. Therefore, in the years that followed we conducted a study whose primary goal was to establish the safety and efficacy of the use of TEP-IHR (with replacement therapy) in patients with congenital bleeding disorders. Like Goldmann et al. in 2010 [25], we reported no deaths, but our study included patients scheduled for inguinal hernia elective surgery. It is therefore difficult to compare our results directly to literature records that refer to less homogeneous groups of patients. However, according to literature data, the mortality rate for surgical patients with bleeding disorders and ongoing replacement therapy (RT) ranges from $1.4 \%$ to $9 \%$ [19-22]. We observed no life-threatening bleeding complications or need for red blood cell (RBC) transfusions in patients with bleeding disorders. The incidence rate for local hematomas did not differ significantly between the $\mathrm{H}$ group and $\mathrm{NH}$ group $-18.2 \%$ and $13.9 \%$ respectively. Our results are consistent with those presented in similar studies which evaluate surgical management of hemophilia patients with RT support [5, 25-34]. However, the percentage of local hematomas for both $\mathrm{H}$ and $\mathrm{NH}$ patients is higher than that reported in the literature for corresponding groups of patients: $5-10 \%$ for patients with bleeding disorders $[5,24,26]$ and an average of $8 \%$ for patients with no hemorrhagic 
disorders [26, 29-31]. Duration of unilateral and bilateral hernia surgery in the study groups was similar and there was no significant difference in median duration. This leads to the conclusion that hemorrhagic disorder in patients undergoing TEP-IHR with adequate RT support does not impede surgery. Prolonged hospitalization for our study patients with hemorrhagic disorders was justified by the need to control RT. Return to preoperative activity was mostly observed on the third postoperative day. In the $\mathrm{NH}$ study group however the frequency was significantly higher, which may be explained by the different health status. Delayed return to preoperative activity in the $\mathrm{H}$ group may be associated with hemorrhagic disorder and in some cases with arthropathy as one of the complications of hemophilia. Pain intensity and the need of analgesics during the first postoperative week were low and did not differ significantly between study groups. This is consistent with the results of TEP-IHR evaluation studies [7, 26, 29-34]. The significantly higher pain intensity reported by patients with bleeding disorders 1 month after surgery is difficult to interpret because we do not know of any similar studies which evaluated postoperative pain in patients with and without bleeding disorders. The advantage of our study is that it was conducted prospectively with a control group in patients with hemorrhagic disorders, operated on due to one disease - inguinal hernia. On the other hand, its disadvantage is the small number of participants. It should be noted however that surgical management of patients with bleeding disorders is a great challenge and procedures of this type are seldom performed, so the study outcome usually regards relatively small and often heterogeneous groups of patients. It would therefore be warranted to verify the results provided by our interdisciplinary team on a larger group of patients from other hemophilia comprehensive care centers.

\section{Conclusions}

In hemophilia and von Willebrand patients with clotting factor supplementation totally extraperitoneal inguinal hernia repair is not associated with higher risk of bleeding complications than in patients without bleeding disorders.

In hemophilia and von Willebrand patients totally extraperitoneal inguinal hernia repair with clotting factor supplementation is feasible and as effective for prevention of hernia recurrence as in patients without bleeding disorders.

In hemophilia and von Willebrand patients totally extraperitoneal inguinal hernia repair with clotting factor supplementation is burdened with a comparable demand for painkillers but with higher pain intensity as in non-hemophiliac patients.

Hospitalization and recovery in hemophilia and von Willebrand patients were recorded as significantly longer than for non-hemophiliac patients.

\section{Conflict of interest}

The authors declare no conflict of interest.

\section{References}

1. HerniaSurge Group. International guidelines for groin hernia management. Hernia 2018; 22: 1-165.

2. Mitura K, Śmietański M, Kozieł S, et al. Factors influencing inguinal hernia symptoms and preoperative evaluation of symptoms by patients: results of a prospective study including 1647 patients. Hernia 2018; 22: 585-91.

3. Atkinson TM, Giraud GD, Togioka BM, et al. Cardiovascular and ventilatory consequences of laparoscopic surgery. Circulation 2017; 135: 700-10.

4. Zychowicz A, Radkowiak D, Lasek A, et al. Laparoscopic splenectomy for immune thrombocytopenia in patients with a very low platelet count. Videosurgery Miniinv 2018; 13: 157-63.

5. Lingohr P, Bensoukehal S, Matthaei $\mathrm{H}$, et al. Value and risk of laparoscopic surgery in hemophiliacs-experiences from a tertiary referral center for hemorrhagic diatheses. Langenbecks Arch Surg 2014; 399: 609-18.

6. Ingerslev J, Hvid I. Surgery in hemophilia. The general view: patient selection, timing, and preoperative assessment. Semin Hematol 2006; 43(1 Suppl 1): S23-6.

7. Pielaciński K, Puła B, Wróblewski T, et al. Totally extraperitoneal inguinal hernia repair with or without fixation leads to similar results. Outcome of randomized prospective trial. Videosurgery Miniinv 2020; 15: 1-10.

8. Rudowski WJ. Moynihan Lecture, 1980. Major surgery in haemophilia. Ann R Coll Surg Engl 1981; 63: 111-7.

9. Sadler JE, Budde U, Eikenboom JC, et al. Update on the pathophysiology and classification of von Willebrand disease: a report of the Subcommittee on von Willebrand factor. J Thromb Haemost 2006; 4: 2103-14.

10. Nichols WL, Hultin MB, James AH, et al. von Willebrand disease (VWD): evidence-based diagnosis and management guidelines, the National Heart, Lung, and Blood Institute (NHLBI) Expert Panel report (USA). Haemophilia 2008; 14: 171-232.

11. Windyga J, Chojnowski K, Kulkowska A, et al. Part I: Guidelines on the management of Haemophilia $A$ and $B$ without factor VIII or IX inhibitors (updated edition). Acta Haematol Pol 2016; 47: 86-114.

12. Srivastava A, Brewer AK, Mauser-Bunschoten EP, et al. Guidelines for management of haemophilia. Haemophilia 2013; 19: e1-47. 
13. Rocino A, Coppola A, Franchini M, et al. Principles of treatment and update of recommendations for the management of haemophilia and congenital bleeding disorders in Italy. Blood Trans 2014; 12: 575-98.

14. Szczepanik AB, Wislawski S, Windyga J, et al. Strategy for secure hemostasis in hemophilia patients undergoing surgery for malignant neoplasms. Pol Merkur Lek 2009; 27: 375-80.

15. Mitura K, Dąbrowiecki S, Śmietański M, Matyja A. The experience and awareness of laparoendoscopic procedures among Polish surgeons in everyday clinical practice. Videosurgery Miniinv 2017; 12: 13-8.

16. Hermans C, Altisent C, Batorova A, et al. Replacement therapy for invasive procedures in patients with haemophilia: literature review. European survey and recommendations. Haemophilia 2009; 15: 639-58.

17. Putnis S, Berney CR. Totally extraperitoneal repair of inguinal hernia: techniques and pitfalls of a challenging procedure. Langenbecks Arch Surg 2012; 397: 1343-51.

18. Miserez M, Alexandre JH, Campanelli G, et al. The European hernia society groin hernia classification: simple and easy to remember. Hernia 2007; 11: 113-6.

19. Brown B, Steed DL, Webster MW, et al. General surgery in adult haemophiliacs. Surgery 1986; 99: 154-9.

20. Bastounis E, Pikoulis E, Leppaniemi A, et al. General surgery in haemophiliac patients. Postgrad Med J 2000; 76: 494-5.

21. Craddock CGFL Jr, Simmons B. Hemophilia: problem of surgical intervention for accompanying diseases. Review of the literature and report of a case. Ann Surg 1948; 128: 888-903.

22. Aryal KR, Wiseman, D, Siriwardena, AK. et al. General surgery in patients with a bleeding diathesis: how we do it. World J Surg 2011; 35: 2603-10.

23. Coppola A, Windyga J, Tufano A, et al. Treatment for preventing bleeding in people with haemophilia or other congenital bleeding disorders undergoing surgery. Cochrane Database Syst Rev 2015; 9: CD009961.

24. Rodriguez-Merchan EC. Surgical wound healing in bleeding disorders. Haemophilia 2012; 18: 487-90.

25. Goldmann G, Holoborodska Y, Oldenburg J, et al. Perioperative management and outcome of general and abdominal surgery in hemophiliacs. Am J Surg 2010; 199: 702-7.

26. Gong K, Zhang N, Lu Y, et al. Comparison of the open tension-free mesh-plug, transabdominal preperitoneal (TAPP), and totally extraperitoneal (TEP) laparoscopic techniques for primary unilateral inguinal hernia repair: a prospective randomized controlled trial. Surg Endosc 2011; 25: 234-9.

27. Rogenhofer S, Hauser S, Breuer A, et al. Urological surgery in patients with hemorrhagic bleeding disorders hemophilia A, hemophilia B, von Willebrand disease: a retrospective study with matched pairs analysis. World J Urol 2013; 31: 703-7.

28. Chapin J, Bamme J, Hsu F, et al. Outcomes in patients with hemophilia and von Willebrand disease undergoing invasive or surgical procedures. Clin Appl Thromb Hemost 2017; 23: 148-54.

29. Eklund A, Rudberg C, Leijonmarck CE, et al. Recurrent inguinal hernia: randomized multicenter trial comparing laparoscopic and Lichtenstein repair. Surg Endosc 2007; 21: 634-40.

30. Pokorny H, Klingler A, Schmid T, et al. Recurrence and complications after laparoscopic versus open inguinal hernia repair: results of a prospective randomized multicenter trial. Hernia 2008; 12: 385-9.

31. Wake BL, McCormack K, Fraser C, et al. Transabdominal pre-peritoneal (TAPP) vs totally extraperitoneal (TEP) laparoscopic techniques for inguinal hernia repair. Cochrane Database Syst Rev 2005; 25: CD004703.

32. Mitura K, Garnysz K, Wyrzykowska D, Michatek I. The change in groin pain perception after transabdominal preperitoneal inguinal hernia repair with glue fixation: a prospective trial of a single surgeon's experience. Surg Endosc 2018; 32: 4284-9.

33. Yildirim D, Donmez T, Ozcevik H, et al. Comparison of slit mesh versus nonslit mesh in laparoscopic extraperitoneal hernia repair. Videosurgery Miniinv 2018; 13: 469-76.

34. Białecki J, Myszka W, Wysocka E, et al. A comparison of the oxidative stress response in single-incision laparoscopic versus multi-trocar laparoscopic totally extraperitoneal inguinal hernia repair. Videosurgery Miniinv 2020; 15: 567-73.

Received: 9.11.2020, accepted: 23.12.2020 